\title{
Removal of Grit from Baby Leafy Salad Vegetables by Combinations of Sanitiser and Surfactant
}

\author{
Vongai Dakwa $\mathbb{D}^{D}$, Alieta Eyles $(\mathbb{D}$, Alistair Gracie, Mark Tamplin, and Tom Ross $(\mathbb{D}$ \\ ARC Training Centre for Innovative Horticultural Products, Tasmania Institute of Agriculture, University of Tasmania, \\ Private Bag 54, Hobart, Tasmania 7001, Australia
}

Correspondence should be addressed to Vongai Dakwa; vongai.dakwa@utas.edu.au

Received 22 March 2019; Revised 12 June 2019; Accepted 3 July 2019; Published 4 August 2019

Academic Editor: M. Teresa Sánchez-Ballesta

Copyright $(92019$ Vongai Dakwa et al. This is an open access article distributed under the Creative Commons Attribution License, which permits unrestricted use, distribution, and reproduction in any medium, provided the original work is properly cited.

Grit composed of dirt, sand, and small stones adheres to baby leafy salad vegetables during the growing period and can sometimes be difficult to remove with sanitiser only or tap water. For the first time, the effect of a surfactant, sodium dodecyl sulphate (SDS), alone $(0.025,0.05$, and $0.1 \%$ SDS $)$ and in combination $(0.05 \%$ SDS $)$ with peroxyacetic acid $\left(40 \mathrm{mg} \cdot \mathrm{L}^{-1}, \mathrm{PAA}\right)$, on grit removal, quality, shelf-life, and taste of baby spinach was investigated. Increasing SDS from 0.025 to $0.1 \%$ resulted in a $21-50 \%$ increase in grit removal from spinach and coral lettuce. Overall, SDS treatments had no effect on microbial growth, colour, and electrolyte leakage during shelf-life. An increase in bruising, sliming, and yellowing scores was also observed regardless of the treatment, reaching an unacceptable score $(<3)$ by $\mathrm{d} 12$ for all samples; however, yellowing scores were still within the acceptable range $(>3)$ on d14. There were no differences in sensorial attributes, namely, flavour, aroma, and texture, between baby spinach samples treated with PAA alone or in combination with SDS. These results demonstrate that SDS treatment can be used to increase grit removal from baby leafy salad vegetables without compromising quality.

\section{Introduction}

Baby leafy salad vegetables are minimally processed, which includes washing them with a sanitiser to minimise microbial cross-contamination and to reduce microbial load, pesticide residues, soil, and grit [1]. Therefore, sanitising improves customer satisfaction, convenience, and visual appeal [2, 3]. Grit can attach to leafy vegetables grown in the open field, through wind, splashing from rain and irrigation, or mechanical harvesting, and can contaminate produce [4]. Grit increases the hydrophobic properties of the leaf surface and thus hinders direct contact between the leaf surface and sanitiser wash water, reducing decontamination efficacy $[5,6]$. Furthermore, grit can harbour microorganisms and therefore facilitate their attachment to produce surfaces [5]. Ingestion of improperly washed leafy vegetables with grit and soil can have a negative impact on health, if the soil has pathogenic microorganisms, heavy metals, pesticides, or fertilisers [7]. Surfactants have been suggested to facilitate removal of bound contaminants from fresh produce surfaces [8].
Surfactants are amphiphilic molecules that reduce interfacial/surface tension of solutions [8-10]. They consist of a nonpolar group attached to a polar group that can either be cationic, anionic, zwitterionic, or nonionic [11]. Surfactants may enhance contact between the sanitiser and microorganisms, thus improving microbial inactivation $[5,12]$, and can enable sanitisers to gain access to crevices and cracks in the lettuce (Lactuca sativa var. crispa) structure [13]. Raiden et al. [14] states that detergents can successfully clean produce without compromising its structural integrity. SDS is a food-grade anionic surfactant that has previously been used with leafy salad vegetables $[5,15,16]$. Huang and Nitin [5] observed that sodium dodecyl sulphate (SDS), Tween 20 , and lauric arginate at $0.1 \%$ lowered the surface tension of water from $71.17 \mathrm{mN} \cdot \mathrm{m}^{-1}$ to $46.6,36$, and $36 \mathrm{mN} \cdot \mathrm{m}^{-1}$, respectively. In the same study, soil particles reduced the ability of the surfactants SDS, lauric arginate, and Tween 20 to remove Escherichia coli O157:H7-lux and Listeria innocua from the romaine lettuce leaf surface by $0.2-0.5$ and $0.7-0.8 \log \mathrm{CFU} \cdot \mathrm{cm}^{-2}$, respectively, compared to 
control lettuce leaves without soil. Xiao et al. [10] demonstrated the importance of using surfactants at concentrations exceeding the critical micelle concentration in order to realise their benefits.

The efficacy of a wide range of surfactants to inactivate bacteria and viruses, alone and in combination with sanitisers, on leafy salad vegetables has been examined with varying results. Baby spinach leaves (Spinacia oleracea) inoculated with E. coli O157:H7 showed a 3.1 log CFU.leaf ${ }^{-1}$ reduction following treatment with $1 \%$ thiamine dilauryl sulphate (TDS) in comparison with a simple water wash and a further $1.4 \log$ CFU.leaf ${ }^{-1}$ reduction during $7 \mathrm{~d}$ of shelf-life [17]. In contrast, $0.1 \%$ SDS and $0.1 \%$ Tween 80 did not increase the removal of Salmonella sp. and Shigella sp. from green-leafy lettuce surfaces compared to tap water [14]. The combination of surfactants and sanitisers has not always been beneficial. For example, Zhao et al. [15] observed 4.2-4.5 $\log$ CFU. ${ }^{-1}$ reduction of S. enteritis, S. typhimurium, and E. coli $\mathrm{O} 157: \mathrm{H} 7$ on inoculated romaine lettuce after treatment with 0.3 and $0.5 \%$ levulinic acid in combination with $0.05 \%$ SDS for $1 \mathrm{~min}$ at $21^{\circ} \mathrm{C}$. However, Keskinen and Annous [18] observed $0.85-1 \log \mathrm{CFU} \cdot \mathrm{g}^{-1}$ reduction of E. coli $\mathrm{O} 157: \mathrm{H7}$ on inoculated romaine lettuce after treatment with chlorine-based sanitisers, and their efficacy was not improved with addition of either $0.2 \%$ dodecylbenzenesulphonic acid or sodium 2-ethyl hexyl sulphate surfactants for $2 \mathrm{~min}$ at $22^{\circ} \mathrm{C}$.

Sanitisers for fresh produce include chlorine dioxide, hydrogen peroxide, PAA, ozone, electrolysed oxidizing water, and organic acids $[3,19,20]$. PAA is a nonfoaming strong oxidant composed of hydrogen peroxide and acetic acid in an equilibrium mixture and decomposes into benign products that include water, acetic acid, carbon dioxide, and oxygen $[21,22]$. The PAA sanitiser is preferred over chlorine, as chlorine reacts with organic matter to form trihalomethanes which are potentially harmful to human health [23].

Despite the presence of grit affecting consumer acceptability, no other studies have considered and quantified the efficacy of SDS alone and in combination with the sanitiser, peroxyacetic acid (PAA), on the removal of grit from vegetables and fruit in general including leafy salad vegetables. Most of the studies cited above focused on the effect of surfactants on microbial safety, very few of these studies assessed shelf-life and sensory quality $[13,16]$, and none involved tasting.

The main objective of this study was to evaluate the effect of SDS treatment alone and in combination with PAA (15.2\%) on grit removal, microbial quality, sensorial attributes, and shelf-life of baby leafy salad vegetables. Two leaf varieties were selected based on their difference in morphology: baby spinach (Spinacia oleracea) representing flat leaf varieties and coral lettuce (Lactuca sativa var. crispa) representing curly leaves. The investigation was divided into two stages, involving the initial work to identify effective concentrations of SDS, namely, $0.025 \% 0.05 \%$, and $0.1 \%$, on baby spinach and coral lettuce. A subsequent experiment involved a shelf-life study of baby spinach treated with tap water as the control, PAA alone, and 0.05\% SDS + PAA including organoleptic evaluation.

\section{Materials and Methods}

2.1. Plant Materials. Fresh baby spinach and coral lettuce were harvested manually from a commercial farm in Tasmania, Australia (Richmond latitude: $42^{\circ} 44^{\prime} 2.40^{\prime \prime} \mathrm{S}$ and longitude: $147^{\circ} 26^{\prime} 24.00^{\prime \prime} \mathrm{E}$ ) at a maturity stage of $40-100 \mathrm{~mm}$ length. Given the nature of the study, the plant material with a high load of grit was selected. Samples were transported to the laboratory in an ice box taking no longer than $40 \mathrm{~min}$. Upon arrival, bruised leaves were manually removed. The baby leaves were stored at $4^{\circ} \mathrm{C}$ for a maximum of $16 \mathrm{~h}$ before use in experiments 1 and 2 .

2.2. Preparation of Treatment Solutions. Wash solutions were prepared using potable tap water, Tsunami 100 (active compound: peroxyacetic acid (PAA) at 15.2\%; Ecolab, Minnesota, USA), and sodium dodecyl sulphate (SDS; Sigma-Aldrich, St Louis, MO, USA) (Table 1). In both experiments, potable tap water was used as the control, and the concentration of PAA used was $40 \mathrm{mg} \cdot \mathrm{L}^{-1}$.

Treatment solutions were stored overnight at $4^{\circ} \mathrm{C}$. The $\mathrm{pH}$, oxidation-reduction potential (ORP), and turbidity of the solutions were measured by a $\mathrm{pH}$ meter (Orion 250A, USA), an ORP meter (Milwaukee MW500, Romania), and a turbidity meter (Hach 2100P, USA), respectively.

2.3. Sanitising Treatment of Baby Spinach and Lettuce. All batches of samples were immersed for $45 \mathrm{~s}$ in processing wash water containing sanitising solution with or without SDS in a ratio of $1: 30$ (produce : water, w/v). In experiment 1 , each batch involved washing $30 \mathrm{~g}$ of baby spinach and lettuce separately in $900 \mathrm{~mL}$ of solution, whereas in experiment 2, $100 \mathrm{~g}$ of baby spinach was washed in $3 \mathrm{~L}$ wash water. Excess wash water was removed manually with a manual salad spinner and spun three times (8 revolutions/ spin on average). The wash water was collected to allow measurement of total grit removed. Out of the three SDS concentrations tested in experiment $1,0.1 \%$ SDS produced the most foam; therefore, $0.05 \%$ SDS was selected for experiment 2 .

Total grit removed was quantified by filtering the wash water through Whatman filter paper no. $1(18.5 \mathrm{~cm})$ by gravity; these filter papers were oven-dried until constant weight at $80^{\circ} \mathrm{C}$. Wash solutions from experiment 2 were double-filtered, using fast flowing fluted VWR filter paper $415(38.5 \mathrm{~cm})$ first and then medium-fast flowing fluted Whatman filter paper no. $1(24 \mathrm{~cm})$ to capture smaller particles. The amount of grit removed was expressed as g per $\mathrm{g}$ of fresh leaf biomass:

$$
\text { grit removed }=\frac{N_{\max }}{\left(1+\left(N_{\max } / N_{\min }\right)-1\right) * e^{(- \text {rate } * \% \mathrm{SDS})}},
$$

where $N_{\max }=$ maximum grit that can be removed by $0.1 \%$ SDS (0.0106 and 0.0141), $N_{\min }=$ minimum grit that can be removed by tap water $(0.00679$ and 0.00977$)$, and rate $=33.9$ and 38.5 for spinach and coral lettuce, respectively.

For experiment 2, $40 \mathrm{~g}$ of processed baby spinach was packed manually in oriented polypropylene (OPP) film 
TABLE 1: Details of variety of leafy salad vegetables and concentrations of surfactant and sanitiser solutions used for experiments 1 and 2.

\begin{tabular}{lcccc}
\hline \multirow{2}{*}{ Experiment number } & \multirow{2}{*}{ Baby leafy vegetable } & \multicolumn{3}{c}{ Treatment solutions } \\
& Control & \% SDS (w/v) & PAA $\left(40 \mathrm{mg} \cdot \mathrm{L}^{-1}\right)$ & PAA + 0.05\% SDS \\
\hline 1 & Spinach and coral lettuce & $\checkmark$ & 0.025 & - \\
& & & 0.05 & - \\
2 & Spinach & $\checkmark$ & - & $\checkmark$ \\
\hline
\end{tabular}

(Apex Films, Victoria, Australia) bags $(28 \times 16 \mathrm{~cm})$. Bags were stored at $4^{\circ} \mathrm{C}$ for subsequent quality assessment during a $14 \mathrm{~d}$ shelf-life trial.

On days $0,4,7,10$, and 14 , three bags per treatment were analysed for microbial load, whereas five bags per treatment were assessed for electrolyte leakage and colour measurements. Prior to washing, samples were also analysed for microbial load on the day of processing. The organoleptic properties of the samples were evaluated during shelf-life as described below.

2.4. Microbial Analysis. Ten grams of samples from each package were transferred aseptically to sterile filter bags $(190 \times 300 \mathrm{~mm})$, diluted $1: 10(\mathrm{w} / \mathrm{w})$ in $0.1 \%$ sterile buffered peptone water (Oxoid LP0037, UK), and homogenised for $120 \mathrm{~s}$ using a stomacher (Colworth Stomacher 400, Seward, London, UK). Subsequently, serial decimal dilutions in peptone were performed, and appropriate dilutions were surface-plated on tryptone soya agar (TSA) (Oxoid CM0129, Basingstoke, Hampshire, England) and Pseudomonas agar (Oxoid CM0559, Basingstoke, Hants, UK) for enumeration of total aerobic plate count (TPC) $(72 \mathrm{~h}$ at $25^{\circ} \mathrm{C}$ ) and Pseudomonas spp. ( $48 \mathrm{~h}$ at $\left.25^{\circ} \mathrm{C}\right)$, respectively. Microbial populations were expressed as $\log \mathrm{CFU} \cdot \mathrm{g}^{-1}$ of spinach.

2.5. Colour Measurements. Colour changes of baby spinach, $L^{*}$ for lightness (ranging from 0 for black to 100 for white), $a^{*}$ (degree of redness $a+$ or greenness $a-$ ), and $b^{*}$ (degree of yellowness $b+$ or blueness $b-$ ), were assessed during shelflife. Measurements were taken at two different points on the upper surface of 15 different leaves per treatment using a colourimeter (Konica Minolta Chroma Meter CR-400, Washington, USA) with an $8 \mathrm{~mm}$ diameter viewing aperture.

2.6. Electrolyte Leakage. Following a modified method of Lopez-Galvez [20], electrolyte leakage was measured using a conductivity-TDS-pH-temperature instrument (WP-81 version 6, TPS, Brisbane, Australia). Samples $(2 \mathrm{~g})$ were cut approximately into $1 \mathrm{~cm}^{2}$ squares and immersed in $40 \mathrm{~mL}$ of distilled water at room temperature for $1 \mathrm{~h}$ to obtain the initial electrical conductivity of each solution $\left(C_{1}\right)$ and of distilled water $\left(C_{0}\right)$. Samples were then frozen at $-18^{\circ} \mathrm{C}$ for $24 \mathrm{~h}$, and the total conductivity $\left(C_{2}\right)$ was measured after thawing in water at room temperature for $3 \mathrm{~h}$. Tissue electrolyte leakage was calculated using the following formula:

$$
E=\left(\frac{C_{1}-C_{0}}{C_{2}}\right) * 100
$$

2.7. Organoleptic Evaluation. For experiment 2, visual quality assessment of nine samples (3 replicates per treatment) was conducted by a panel of up to seven trained members on $0,3,7,10$, and $14 \mathrm{~d}$ of the shelf-life experiment. Quality deterioration parameters (bruising, sliming, and yellowing) were evaluated on a scale of 1-5, with 5 being the highest quality (no defects and no yellowing), 1 the lowest quality, and 3 commercially acceptable.

The sensory panel test was performed for samples treated with $40 \mathrm{mg} \cdot \mathrm{L}^{-1}$ PAA (considered as the control treatment) and $40 \mathrm{mg} \cdot \mathrm{L}^{-1} \mathrm{PAA}+0.05 \%$ SDS. Because of food safety reasons, samples washed with portable water only were not included for tasting. Samples were stored at $4^{\circ} \mathrm{C}$ for $48-64 \mathrm{~h}$ and removed from the fridge before serving. $48-64 \mathrm{~h}$ is the shortest time taken for the packaged product to reach the consumer after processing. During the evaluation, two samples treated with PAA and the other treated with PAA + SDS were served at the same time to 34 panelists. Coded samples were rated on flavour, aroma, texture, and overall liking on a 9-point hedonic scale of 1-9 (dislike extremely-like extremely). Panelists were also asked to indicate their purchase intent on a scale of 1-5 (definitely would buy-definitely would not buy). This study was approved by the Social Sciences Human Research Ethics Committee, University of Tasmania (ethics reference number H0016331). Written consent to participate was sought from the panelists, specifying that only the sensory evaluation data will be published without identifying individuals involved.

2.8. Statistical Analysis. Data were analysed using the JMP statistical software (version 11; SAS Institute Inc., USA). The relationship between grit removed and \% SDS from experiment 1 was evaluated using regression analysis. For experiment 2, two-way analysis of variance (ANOVA) was used to analyse the following shelf-life data: TPC, Pseudomonas count, electrolyte leakage, and colour parameters, with day and treatment as the independent variables. Grit data were analysed using one-way ANOVA followed by Tukey's honestly significant difference (HSD) test. To understand whether treatment had an effect on taste attributes, data were analysed using the chi-square test in JMP. ANOVA for sensory evaluation data (visual quality assessment) was performed using "proc mixed" in SAS 
(version 9.3; USA), and a random effect was included for the panelist. A repeated-measures approach was assumed with a spatial correlation structure, where the sample code was used as the repeated experimental unit. Assumptions for homogeneity of variance and normality were checked before each analysis. Significance was calculated at $p<0.05$.

\section{Results and Discussion}

3.1. Optimising SDS Concentration for Grit Removal from Baby Spinach and Coral Lettuce. There was a significant positive correlation between the amount of grit removed and $\%$ SDS (Figure 1). $R^{2}$ was higher for coral lettuce than that for spinach $\left(R^{2}\right.$ coral lettuce $=0.734, \quad p<0.0001 ; R^{2}$ spinach $=0.372, p=0.0043)$.

Increasing SDS concentration also resulted in increased foaming. Ho et al. [24] also observed excessive foaming in wash tanks containing 250 ppm SDS in combination with peroxyacetic acid + lactic acid.

\subsection{Effects of PAA + SDS Treatment on Grit Removal, Microbial Load, Shelf-Life, and Taste of Baby Spinach}

3.2.1. Wash Water Characteristics. Addition of SDS to PAA did not influence $\mathrm{pH}$ and ORP values (Table 2), which suggests that SDS does not influence antimicrobial properties of the sanitiser. Zhao et al. [15] observed a $\mathrm{pH}$ of 6 for $0.05 \%$ SDS, 3.0 for levulinic acid (LA), and 3.1 for LA combined with SDS. Guan et al. [16] also observed a $\mathrm{pH}$ of 3.04 for $0.5 \%$ LA $+0.05 \%$ SDS.

Although turbidity values of PAA + SDS solution after washing were higher (195-228 NTU) than those of the control (79 NTU) and PAA solutions (76 NTU) because of the presence of grit, PAA + SDS solution also had high turbidity values (90-114 NTU) even before washing (Supplementary Table S1).

3.2.2. Grit Removed. In experiment 2, the combination of SDS $(0.05 \%)$ and PAA resulted in a significant increase $(p=0.0012)$ in the amount of grit removed as compared to tap water and PAA alone by 19 and 21\%, respectively (Figure 2). Grit removed by tap water and PAA was comparable (Figure 2; $p>0.05$ ). Preliminary trials also proved that SDS alone washed more grit as compared to tap water (similar results to those in Figure 1), and PAA + SDS washed off more grit compared to PAA alone (data not shown).

3.2.3. Microbiological Analysis. The initial TPC of baby spinach was $6.6 \pm 0.1 \mathrm{log} \mathrm{CFU} \cdot \mathrm{g}^{-1}$ (Figure 3 ) with significant reductions of $0.85,1.28$, and $1.50 \log \mathrm{CFU} \cdot \mathrm{g}^{-1}$ observed after washing with tap water, PAA, and PAA + SDS, respectively (Figure $3 ; p<0.001$ ). A progressive increase in TPC from 5.1 to $5.8 \log \mathrm{CFU} \cdot \mathrm{g}^{-1}$ was observed during storage across all treatments, reaching similar levels of $7.9-8.3 \log$ CFU.g ${ }^{-1}$ on d10. Samples washed with tap water alone had $0.4 \log$ CFU.g ${ }^{-1}$ higher counts $(p=0.0002)$ during the first few days of shelf-life in comparison with PAA- and

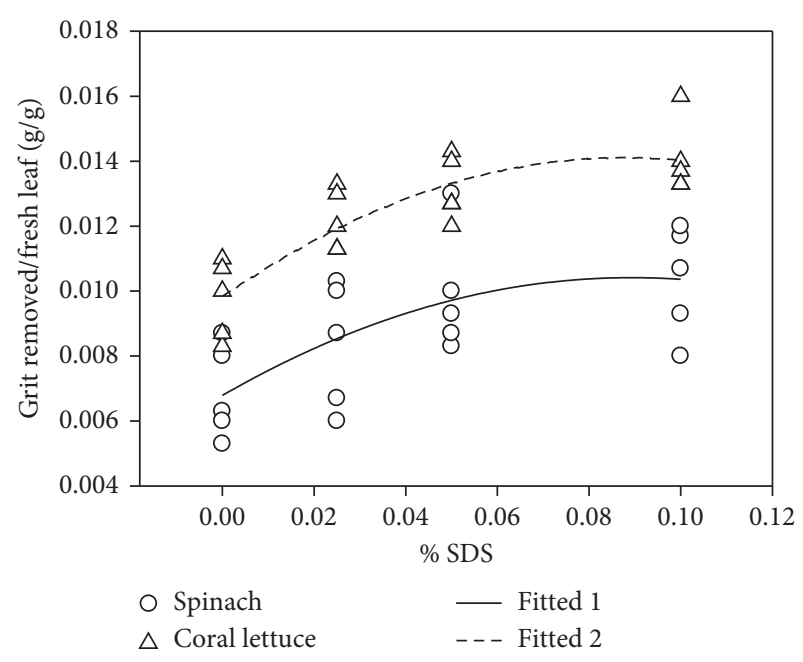

FIGURE 1: Relationship between grit removed per g of coral lettuce and spinach and \% SDS concentration (SDS = sodium dodecyl sulphate).

TABLE 2: $\mathrm{pH}$ and ORP values for wash water solutions used in experiment 2.

\begin{tabular}{lcc}
\hline Wash solution & $\mathrm{pH}$ & ORP \\
\hline Tap water & 6.82 & 363 \\
PAA $\left(40 \mathrm{mg} \cdot \mathrm{L}^{-1}\right)$ & 4.25 & 587 \\
PAA $\left(40 \mathrm{mg} \cdot \mathrm{L}^{-1}\right)+0.05 \%$ SDS & 4.24 & 557 \\
\hline
\end{tabular}

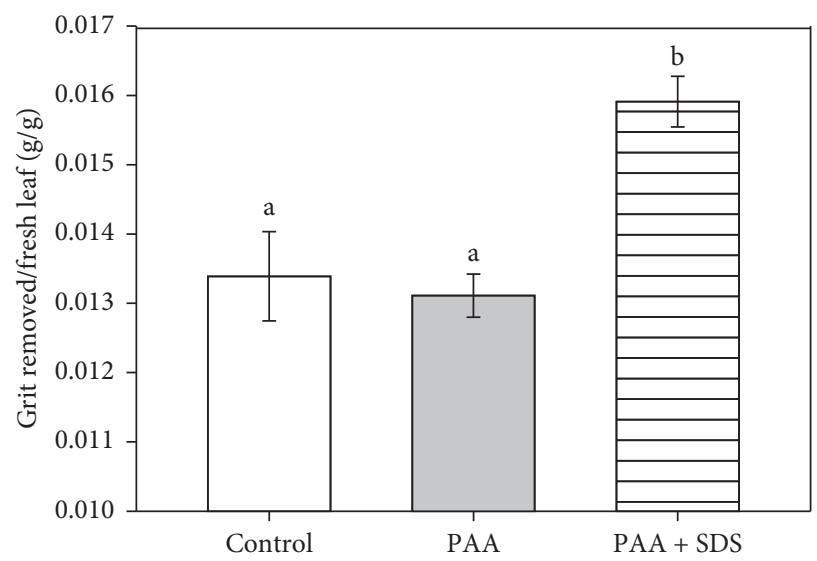

FIGURE 2: Grit removed g/g of baby spinach using washing solution treatments (control = tap water; $40 \mathrm{ppm} \mathrm{PAA;0.05 \%} \mathrm{sodium}$ dodecyl sulphate). Error bars represent standard error of the mean $(n=5)$. Different letters show significant differences at $p<0.05$.

PAA + SDS-treated samples during storage (Figure 3). However, no significant difference $(p>0.05)$ in TPC was observed between PAA- and PAA + SDS-treated spinach throughout the storage period. The initial Pseudomonas count was 5.0-5.5 $\log$ CFU.g ${ }^{-1}$ (Figure 4) with an increase of 2.5-2.9 $\log$ CFU.g ${ }^{-1}$ observed during shelf-life for all treatments. However, there was no significant treatment effect $(p>0.05)$ during storage (Figure 4$)$. The growth trend of Pseudomonas spp. was similar to that of TPC (Figure 3). 


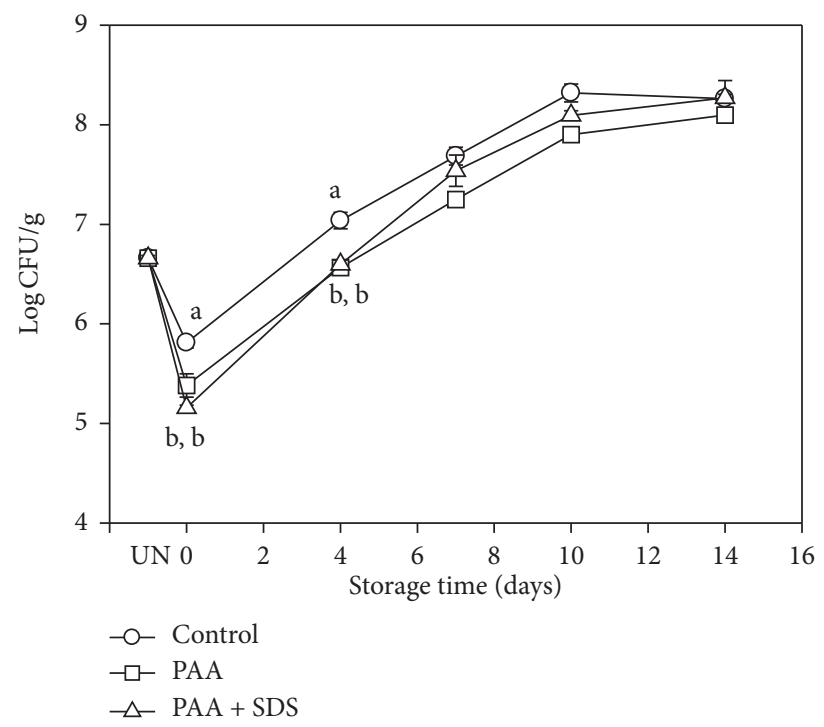

FIGURE 3: Total aerobic plate count of baby spinach leaves treated with tap water (control), peroxyacetic acid (PAA), or peroxyacetic acid + sodium dodecyl sulphate (PAA + SDS), before washing (UN) and after washing during storage at $4^{\circ} \mathrm{C}$ for $14 \mathrm{~d}$. Error bars represent the standard error of the mean $(n=3)$. Different letters show significant differences at $p<0.05$.

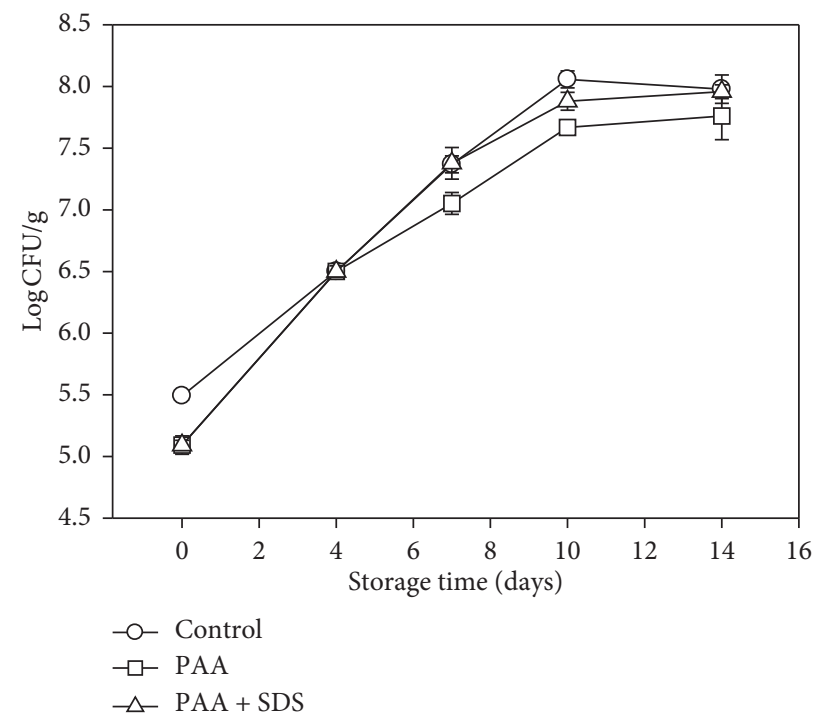

Figure 4: Counts of Pseudomonas spp. on baby spinach leaves treated with tap water (control), peroxyacetic acid (PAA), or peroxyacetic acid + sodium dodecyl sulphate (PAA + SDS), during storage at $4^{\circ} \mathrm{C}$ for $14 \mathrm{~d}$. Error bars represent the standard error of the mean $(n=3)$.

PAA + SDS treatment did not produce higher initial TPC $\log$ reductions or reduce microbial growth during shelf-life in comparison with PAA treatment, and thus, SDS had no effect on microbial quality. Similar results were obtained by Ho et al. [24], whereby $0.02-0.025 \%$ SDS did not improve the efficacy of PAA $\left(70 \mathrm{mg} \cdot \mathrm{L}^{-1}\right)$ and lactic acid $\left(4500 \mathrm{mg} \cdot \mathrm{L}^{-1}\right)$ treatment against E. coli K-12 and L. innocua on inoculated romaine lettuce and spinach. Salgado et al. [13] studied the effect of treating lettuce with $1 \mathrm{~g} \mathrm{~L}^{-1} \mathrm{SDS}+80 \mathrm{ml} \mathrm{L}^{-1}$ Tsunami $100+$ ultrasonication on quality aspects. Treatment of inoculated iceberg lettuce with $0.25 \%$ sodium acid sulphate $+0.5 \%$ SDS resulted in $0.87 \log \mathrm{CFU} \cdot \mathrm{g}^{-1}$ decrease in E. coli $\mathrm{O} 157: \mathrm{H} 7$, similar to $0.94 \log \mathrm{CFU} \cdot \mathrm{g}^{-1}$ observed after treatment with $100 \mathrm{ppm}$ chlorine solution [16]. In the same study, $0.41 \log$ CFU. ${ }^{-1}$ reduction was observed after treatment with $0.5 \% \mathrm{LA}+0.05 \% \mathrm{SDS}$ for $5 \mathrm{~min}$. Using $0.1 \%$ SDS improved the removal of L. innocua from inoculated romaine lettuce by $0.95 \log \mathrm{CFU} \cdot \mathrm{m}^{-2}$ in comparison with deionised water, therefore yielding a total reduction of $1.79 \log \mathrm{CFU} \cdot \mathrm{m}^{-2}$ [5]. In contrast, Zhao et al. [15] observed 4.2-4.5 $\log$ CFU.g ${ }^{-1}$ reduction of Salmonella spp. and E. coli O157:H7 on inoculated romaine lettuce after treatment with 0.3 and $0.5 \%$ levulinic acid in combination with $0.05 \%$ SDS for $1 \mathrm{~min}$ at $21^{\circ} \mathrm{C}$. Therefore, in the literature, there is varying evidence on the effect of surfactants on leafy salad vegetables. 


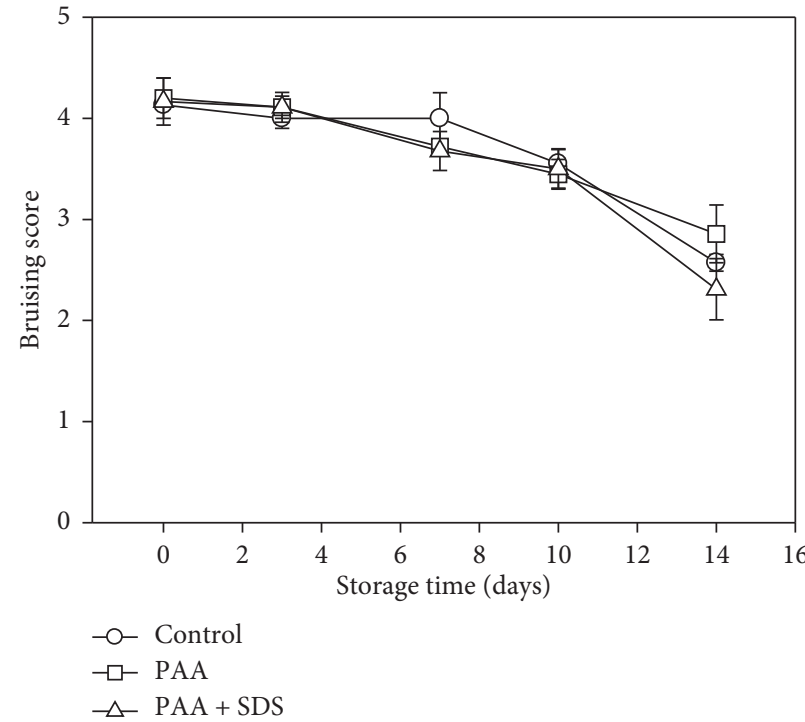

(a)

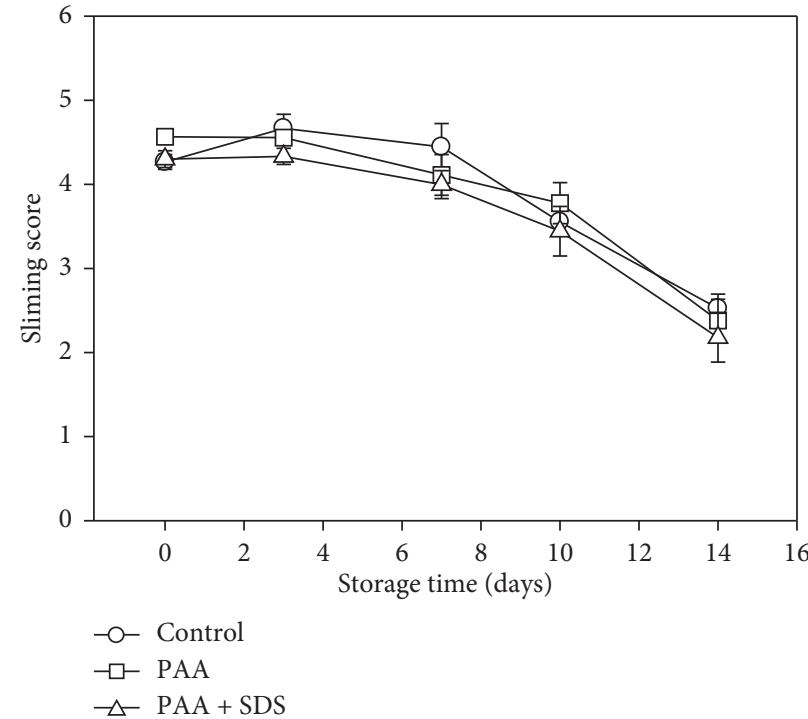

(b)

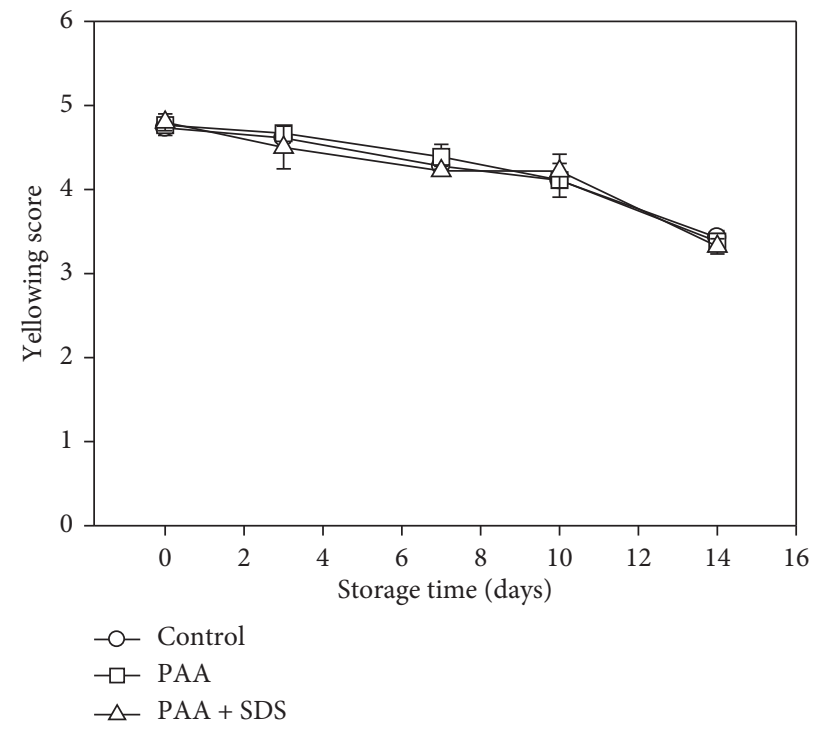

(c)

Figure 5: Changes in sensorial attributes: bruising (a), sliming (b), and yellowing (c) scores for baby spinach samples treated with tap water, peroxyacetic acid (PAA), and peroxyacetic acid + sodium dodecyl sulphate (PAA + SDS), stored at $4^{\circ} \mathrm{C}$ for $14 \mathrm{~d}$. Error bars represent the standard error of the mean ( $n=7$ assessors).

3.2.4. Colour and Electrolyte Leakage. No changes in colour parameters $L^{*}, a^{*}$, and $b^{*}$ were observed during shelf-life across all treatments $(p>0.05)$ (Supplementary Table S2). Huang and Nitin [5] only observed marginal colour changes after washing romaine lettuce with $0.1 \%$ SDS in comparison with water wash.

On each sampling day, there was no significant difference in electrolyte leakage $(p>0.05)$ between treatments (Supplementary Table S3). Electrolyte leakage of romaine lettuce washed with $0.1 \%$ SDS alone was not significantly different from that of the control leaves washed with tap water [5].

3.2.5. Sensory Evaluation. Scores for bruising, sliming, and yellowing of baby spinach were similar across treatments during shelf-life (Figure $5 ; p>0.05$ ). Regardless of the treatment, an increase in bruising and sliming was observed on baby spinach leaves during storage, reaching unacceptable levels $(<3)$ by $\mathrm{d} 12$. Yellowing scores were still within the acceptable range $(\geq 3)$ at the end of shelf-life (Figure 5).

Similarly, Gómez-López [25] observed a decrease in overall quality of baby spinach treated with PAA $\left(80 \mathrm{mg} \cdot \mathrm{L}^{-1}\right)$, during shelf-life from $\mathrm{d} 4$. In contrast, lettuce treated with water and sodium hypochlorite maintained better visual quality compared to lettuce treated with $0.5 \%-3 \%$ levulinic acid $+0.05 \%$ SDS and $0.25-0.75 \%$ sodium acid sulphate $+0.05 \%$ SDS during $14 \mathrm{~d}$ storage period at $4^{\circ} \mathrm{C}[16]$. 


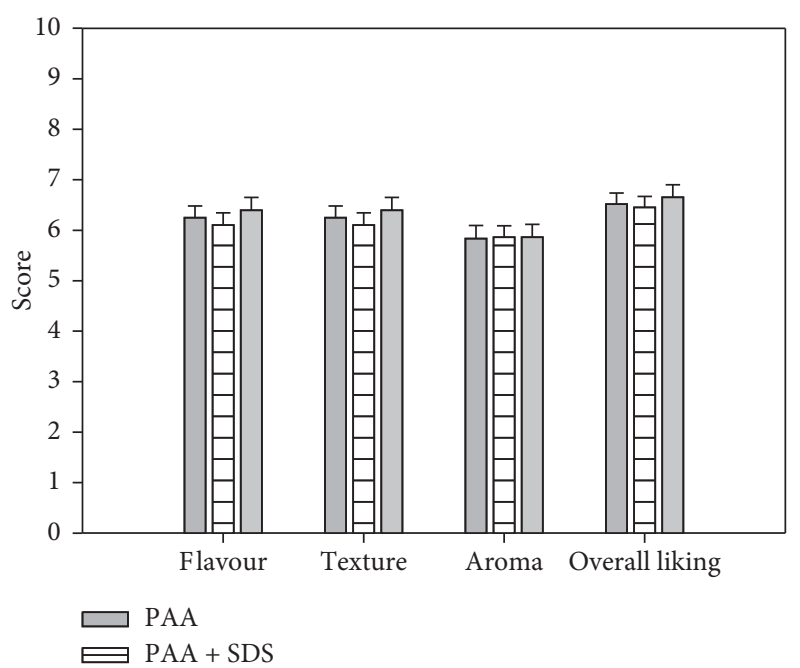

Figure 6: Panel test scores for baby spinach treated with peroxyacetic acid (PAA) and peroxyacetic acid + sodium dodecyl sulphate $(\mathrm{PAA}+\mathrm{SDS})$, stored at $4^{\circ} \mathrm{C}$ for $48-64 \mathrm{~h}$. Error bars represent the standard error of the mean ( $n=30-34$ panelists).

Panelists did not identify any significant differences in taste attribute scores nor overall liking between the spinach samples treated with PAA $\left(40 \mathrm{mg} \cdot \mathrm{L}^{-1}\right)$ and PAA $\left(40 \mathrm{mg} \cdot \mathrm{L}^{-1}\right)+0.05 \%$ SDS (Figure 6; $p>0.05$ ).

Similar results were obtained by Zhou et al. [26] where panelists did not observe differences in flavour, appearance, and texture between strawberries washed with $0.5 \%$ levulinic acid $+0.5 \%$ SDS and $50 \mathrm{~mL}^{-1}$ chlorine solution for $2 \mathrm{~min}$. Though no studies have examined the effect of PAA + surfactant treatment on the taste of leafy vegetables, Ho et al. [24] observed no differences in appearance, colour, aroma, taste, texture, and overall liking of the leaf mix containing spinach, chopped iceberg, and romaine lettuce treated with PAA + lactic acid compared to samples treated with chlorinated water.

Seventy percent of the consumers reported that they would be willing to purchase baby spinach treated with PAA + SDS based on sensorial quality, $21 \%$ were unsure, and only $9 \%$ were unwilling.

\section{Conclusions}

The use of SDS (0.05 and 0.1\%) significantly improved grit removal from baby spinach and coral lettuce in comparison with tap water wash or sanitiser alone. 0.05\% SDS + PAA $\left(40 \mathrm{mg} \cdot \mathrm{L}^{-1}\right)$ treatment aids in grit removal without affecting microbial quality, electrolyte leakage, colour parameters $L^{*}, a^{*}$, and $b^{*}$, shelf-life, and sensorial and organoleptic properties of baby spinach. Future research in this area should consider scaling up to pilot plant with the aim of using low concentrations of SDS to reduce potential foaming issues to assess the feasibility of using SDS in a commercial processing facility.

\section{Data Availability}

The data in tables and figures used to support the findings of this study are included within this article and supplementary materials.

\section{Conflicts of Interest}

The authors declare that there are no conflicts of interest.

\section{Acknowledgments}

We express our sincere gratitude to the Australian Research Council and Woolworths. Thanks are due to Houston's Farm, our industry partner for this project, for their support and provision of materials for the trials. We also thank the sensory panel consisting of UTAS staff and students who participated in organoleptic evaluation. Our gratitude also extends to Dr. Ross Corkrey and Dr. Luwis Diya for advice on statistical analysis. This work was funded by the Australian Research Council's Industrial Transformation Training Centres scheme and Woolworths (grant no. IC140100024).

\section{Supplementary Materials}

Table S1: turbidity values of wash solutions used in experiment 2. Table S2: colour parameters $L^{*}, a^{*}$, and $b^{*}$ of baby spinach leaves treated with tap water (control), peroxyacetic acid (PAA), or peroxyacetic acid + sodium dodecyl sulphate $(\mathrm{PAA}+\mathrm{SDS})$, during storage at $4^{\circ} \mathrm{C}$ for $14 \mathrm{~d}$. Table S3: electrolyte leakage values for baby spinach leaves treated with tap water (control), peroxyacetic acid (PAA), or peroxyacetic acid + sodium dodecyl sulphate (PAA + SDS), during storage at $4^{\circ} \mathrm{C}$ for $14 \mathrm{~d}$. Therefore, in summary, the file contains data on turbidity values for the wash water on the day of processing for experiment 2, colour parameters $L^{*}$, $a^{*}$, and $b^{*}$, and electrolyte leakage values of baby spinach during shelf-life for each treatment. (Supplementary Materials)

\section{References}

[1] K. Joshi, R. Mahendran, K. Alagusundaram, T. Norton, and B. K. Tiwari, "Novel disinfectants for fresh produce," Trends in Food Science \& Technology, vol. 34, no. 1, pp. 54-61, 2013.

[2] Y. J. Jung, A. Padmanabahn, J. H. Hong, J. Lim, and K. O. Kim, "Consumer freshness perception of spinach samples exposed to different storage conditions," Postharvest Biology and Technology, vol. 73, pp. 115-121, 2012.

[3] R. Premier, Evaluation of Vegetable Wash Chemicals, Horticulture Australia Ltd., Sydney, Australia, 2013.

[4] J. W. Rushing, E. A. Bihn, A. E. Brown et al., Improving the Safety and Quality of Fresh Fruits and Vegetables: A Training Manual for Trainers, University of Maryland, College Park, MD, USA, 2010.

[5] K. Huang and N. Nitin, "Enhanced removal of Escherichia coli O157:H7 and Listeria innocua from fresh lettuce leaves using surfactants during simulated washing," Food Control, vol. 79, pp. 207-217, 2017.

[6] A. N. Hassan and J. F. Frank, "Influence of surfactant hydrophobicity on the detachment of Escherichia coli O157:H7 from lettuce," International Journal of Food Microbiology, vol. 87, no. 1-2, pp. 145-152, 2003.

[7] D. Sing and C. F. Sing, "Impact of direct soil exposures from airborne dust and geophagy on human health," International Journal of Environmental Research and Public Health, vol. 7, no. 3, pp. 1205-1223, 2010. 
[8] W. Xu, H. Chen, Y. Huang, and C. Wu, "Decontamination of Escherichia coli $\mathrm{O} 157: \mathrm{H7}$ on green onions using pulsed light (PL) and PL-surfactant-sanitizer combinations," International Journal of Food Microbiology, vol. 166, no. 1, pp. 102-108, 2013.

[9] A. Predmore and J. Li, "Enhanced removal of a human norovirus surrogate from fresh vegetables and fruits by a combination of surfactants and sanitizers," Applied and Environmental Microbiology, vol. 77, no. 14, pp. 4829-4838, 2011.

[10] D. Xiao, R. Ye, P. M. Davidson, D. G. Hayes, D. A. Golden, and Q. Zhong, "Sucrose monolaurate improves the efficacy of sodium hypochlorite against Escherichia coli O157:H7 on spinach," International Journal of Food Microbiology, vol. 145, no. 1, pp. 64-68, 2011.

[11] D. R. Karsa, "What are surfactants?," in Chemistry and Technology of Surfactants, Blackwell Publishing Ltd, Oxford, UK, 2006.

[12] K. Takeuchi and J. F. Frank, "Direct Microscopic Observation of Lettuce Leaf decontamination with a prototype fruit and vegetable washing solution and $1 \% \mathrm{NaCl}-\mathrm{NaHCO}_{3}$.pdf," Journal of Food Protection, vol. 64, no. 8, pp. 1235-1239, 2001.

[13] S. P. Salgado, A. J. Pearlstein, Y. Luo, and H. Feng, "Quality of Iceberg (Lactuca sativa L.) and Romaine (L. sativa $L$. var. longifolial) lettuce treated by combinations of sanitizer, surfactant, and ultrasound," LWT-Food Science and Technology, vol. 56, no. 2, pp. 261-268, 2014.

[14] R. M. Raiden, S. S. Sumner, J. D. Eifert, and M. D. Pierson, "Efficacy of detergents in removing Salmonella and Shigella spp. from the surface of fresh produce," Journal of Food Protection, vol. 66, no. 12, pp. 2210-2215, 2003.

[15] T. Zhao, P. Zhao, and M. P. Doyle, "Inactivation of Salmonella and Escherichia coli O157:H7 on lettuce and poultry skin by combinations of levulinic acid and sodium dodecyl sulfate," Journal of Food Protection, vol. 72, no. 5, pp. 928-936, 2009.

[16] W. Guan, L. Huang, and X. Fan, "Acids in combination with sodium dodecyl sulfate caused quality deterioration of freshcut iceberg lettuce during storage in modified atmosphere package," Journal of Food Science, vol. 75, no. 8, pp. S435S440, 2010.

[17] X. Zhang, X. Fan, D. K. Y. Solaiman et al., "Inactivation of Escherichia coli O157:H7 in vitro and on the surface of spinach leaves by biobased antimicrobial surfactants," Food Control, vol. 60, pp. 158-165, 2016.

[18] L. A. Keskinen and B. A. Annous, "Efficacy of adding detergents to sanitizer solutions for inactivation of Escherichia coli O157:H7 on Romaine lettuce," International Journal of Food Microbiology, vol. 147, no. 3, pp. 157-161, 2011.

[19] L. A. Keskinen, A. Burke, and B. A. Annous, "Efficacy of chlorine, acidic electrolyzed water and aqueous chlorine dioxide solutions to decontaminate Escherichia coli O157:H7 from lettuce leaves," International Journal of Food Microbiology, vol. 132, no. 2-3, pp. 134-140, 2009.

[20] H. Ölmez and U. Kretzschmar, "Potential alternative disinfection methods for organic fresh-cut industry for minimizing water consumption and environmental impact," LWT-Food Science and Technology, vol. 42, no. 3, pp. 686-693, 2009.

[21] F. Artés, P. Gómez, E. Aguayo, V. Escalona, and F. ArtésHernández, "Sustainable sanitation techniques for keeping quality and safety of fresh-cut plant commodities," Postharvest Biology and Technology, vol. 51, no. 3, pp. 287-296, 2009.

[22] G. González-Aguilar, F. J. Ayala-Zavala, C. Chaidez-Quiroz, B. J. Heredia, and N. Castro-del Campo, "Peroxyacetic acid," in Decontamination of Fresh and Minimally Processed Produce, V. M. Gomez-Lopez, Ed., pp. 216-217, John Wiley \& Sons, Hoboken, NJ, USA, 2012.

[23] B. W. Waters and Y.-C. Hung, "The effect of organic loads on stability of various chlorine-based sanitisers," International Journal of Food Science \& Technology, vol. 49, no. 3, pp. 867-875, 2014.

[24] K.-L. G. Ho, D. A. Luzuriaga, K. M. Rodde, S. Tang, and C. Phan, "Efficacy of a novel sanitizer composed of lactic acid and peroxyacetic acid against single strains of nonpathogenic Escherichia coli K-12, Listeria innocua, and Lactobacillus plantarum in aqueous solution and on surfaces of romaine lettuce and spinach," Journal of Food Protection, vol. 74, no. 9, pp. 1468-1474, 2011.

[25] V. M. Gómez-López, A. Marín, M. S. Medina-Martínez, M. I. Gil, and A. Allende, "Generation of trihalomethanes with chlorine-based sanitizers and impact on microbial, nutritional and sensory quality of baby spinach," Postharvest Biology and Technology, vol. 85, pp. 210-217, 2013.

[26] Z. Zhou, S. Zuber, F. Cantergiani et al., "Inactivation of viruses and bacteria on strawberries using a levulinic acid plus sodium dodecyl sulfate based sanitizer, taking sensorial and chemical food safety aspects into account," International Journal of Food Microbiology, vol. 257, pp. 176-182, 2017. 


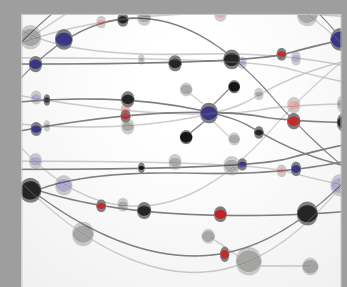

The Scientific World Journal
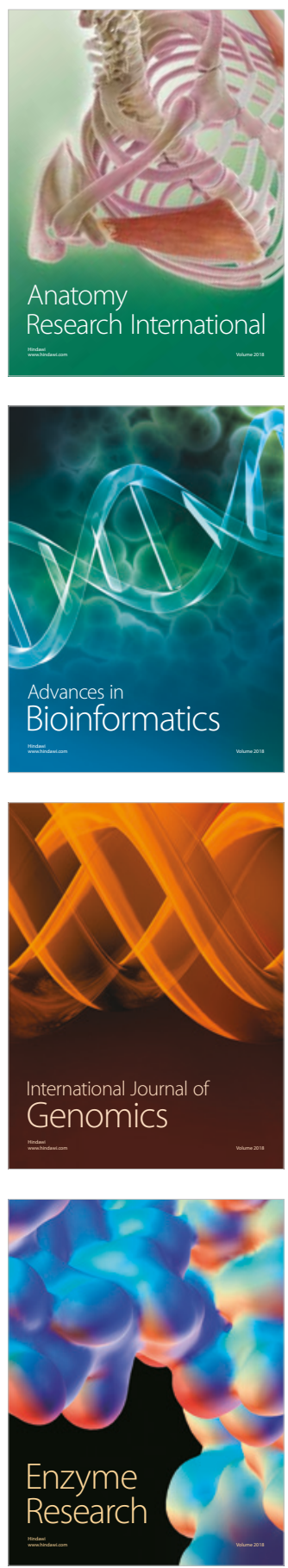
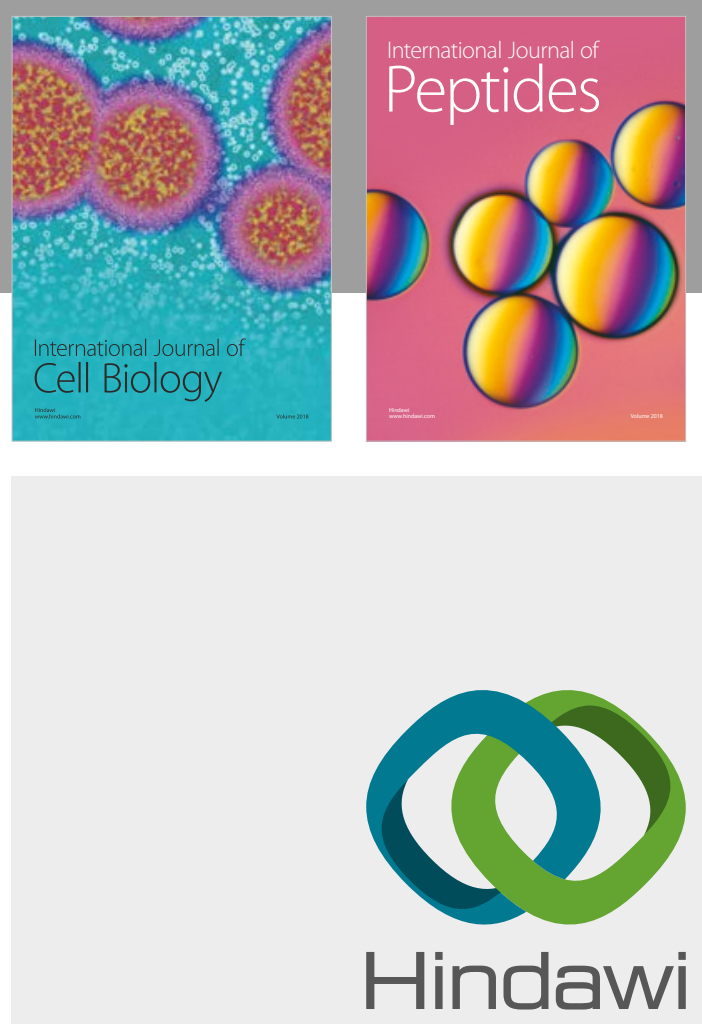

Submit your manuscripts at

www.hindawi.com
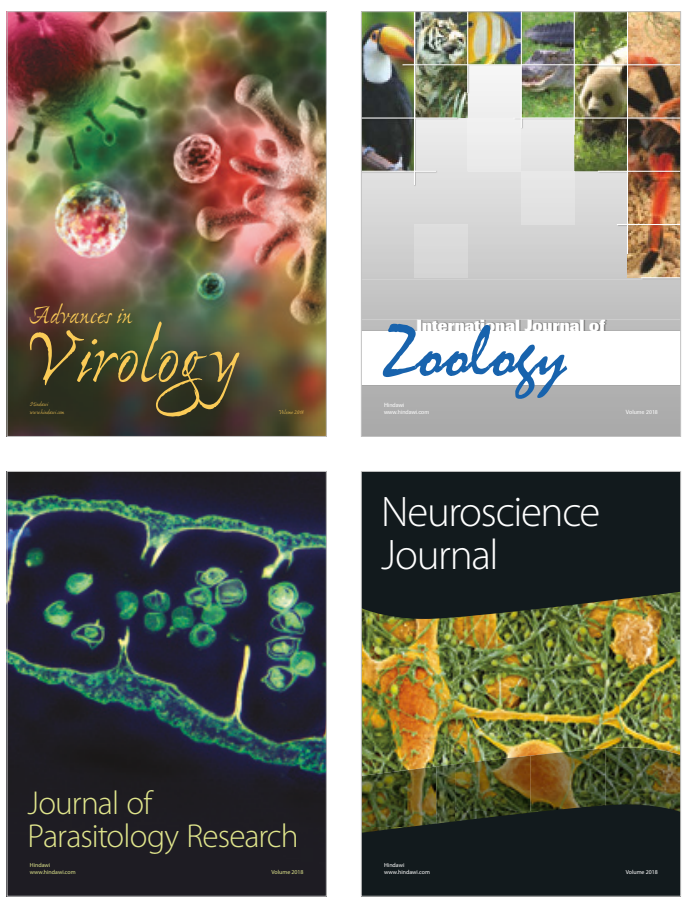
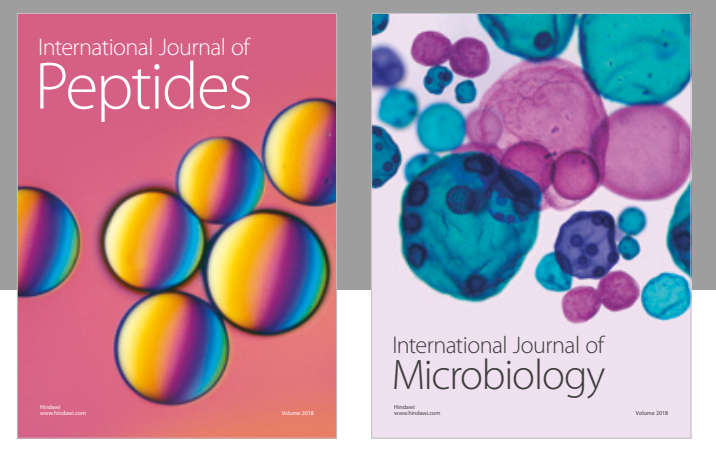

nternational Journal of Microbiology
Journal of
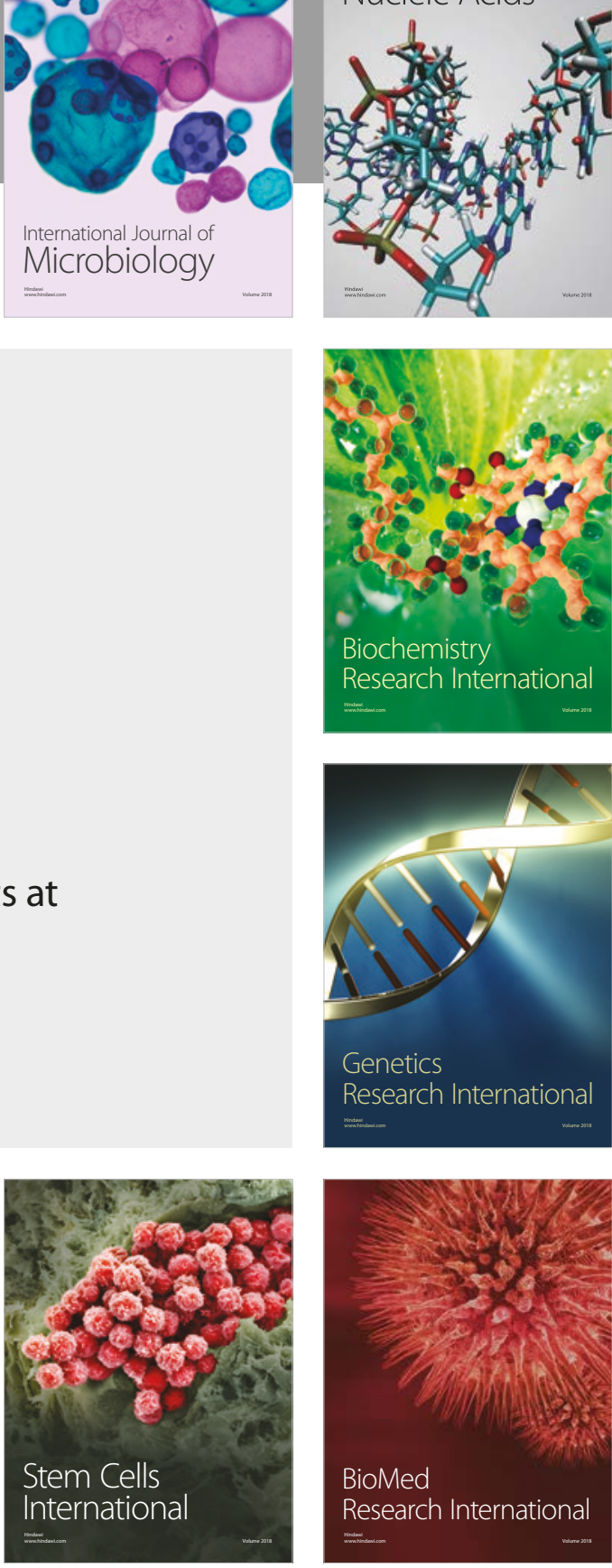
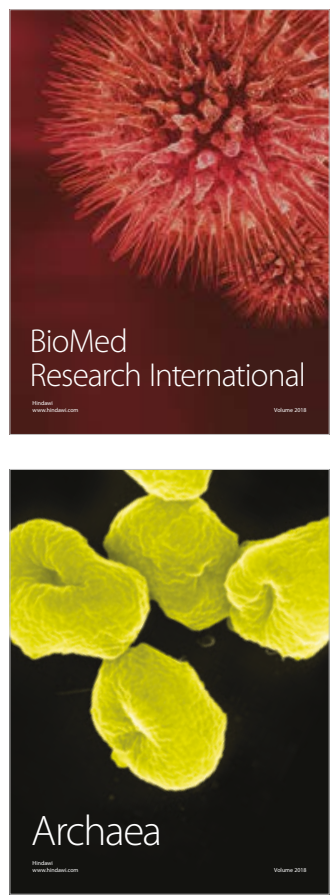